\title{
Documentos curriculares de ensino fundamental 2: uma análise balizada por temas do debate curricular do país
}

Rosário S. Genta Lugli* Hivy Damásio Mello ** Pâmela Felix Freitas*** Luiz Carlos Novaes****

*(Unifesp, São Paulo, SP) Resumo: Este artigo traça uma análise de documentos curriculares de ensino fundamental (EF) 2 de 16 estados

**(Cenpec, São Paulo, SP) brasileiros com base nos seguintes temas: articulação entre conteúdos universais e locais; abordagem da questão da

$\star \star \star(C e n p e c$, São Paulo, SP) diversidade; relações dos documentos com as avaliações externas e tratamento dado às especificidades do EF 2. $\star \star \star \star$ (Unifesp, São Paulo, SP) Conclui-se que a maior parte dos documentos: privilegia conteúdos considerados universais em detrimento da parte diversificada que trataria das questões locais ou regionais; não explicita de forma clara qual é a especificidade do que deve ser aprendido e ensinado no EF 2; menciona de algum modo a questão da diversidade, conforme apregoam os Parâmetros Curriculares Nacionais (PCN) e as Diretrizes Curriculares Nacionais (DNC), mas que há fraca presença de conteúdos que promovam a construção de identidades plurais nas várias disciplinas; e demonstra forte influência das avaliações externas sobre as disciplinas de Língua Portuguesa e Matemática.

Palavras-chave: Currículo. Ensino fundamental II. Diversidade. Avaliação externa. 
Este artigo tem como objetivo analisar documentos curriculares de 16 estados brasileiros $^{1}$ buscando apreender como seus conteúdos ${ }^{2}$ se relacionam com quatro questões consideradas relevantes quando se trata de definições curriculares: como lidam com a diferenciação entre conhecimento universal e local; como abordam a questão da diversidade; que relações estabelecem com a avaliação externa; e que especificidades apresentam para os anos finais do ensino fundamental. Foram analisados 16 conjuntos de documentos curriculares dos seguintes estados: Acre, Alagoas, Bahia, Distrito Federal, Goiás, Maranhão, Mato Grosso, Mato Grosso do Sul, Paraná, Pernambuco, Piauí, Rio de Janeiro, Rio Grande do Sul, Rondônia, São Paulo e Sergipe

\section{ARTICULAÇÃO ENTRE CONTEÚdOS UNIVERSAIS E LOCAIS}

Este tópico almeja explorar como são estabelecidas nos documentos curriculares as relações entre o conhecimento dito universale as especificidades regionais e locais. Ou seja, como os estados tratam a orientação da Lei de Diretrizes e Bases da Educação Nacional (LDB) ${ }^{4}$ de que os documentos curriculares devem conter conteúdos que se reportam a aspectos nacionais e conteúdos que expressam a chamada "parte diversificada", que se reporta a questões regionais e locais.

Selecionaram-se 16 dos 23 conjuntos de documentos estaduais levantados pela pesquisa "Currículos para os anos finais do ensino fundamental: concepções, modos de implantação e usos", da qual este artigo faz parte. O levantamento é compartilhado no artigo "Renovação dos documentos curriculares do ensino fundamental 2 nos estados brasileiros", publicado neste mesmo número da Cadernos Cenpec. Os autores agradecem todos os pesquisadores que participaram desta pesquisa, devidamente listados em CENPEC (2015). Para maiores detalhes sobre a pesquisa e sua metodologia, ver também artigo síntese de Batista et al. (2015).

2 Optou-se por utilizar o termo "conteúdos" no seu sentido amplo para contemplar o que é indicado nos documentos curriculares como o que deve ser ensinado aos alunos ou por eles aprendido (a depender do caso), de modo a dar conta da variedade de termos encontrados (i.e. competências, habilidades, capacidades, conhecimento, expectativas de aprendizagem) diante da falta de homogeneidade dos significados a eles atribuídos. Foram utilizados os seguintes critérios de seleção: propostas produzidas mais recentemente pelos entes federados; propostas em processo de implantação; propostas que não foram analisadas em Sampaio e colaboradores (2010); propostas sem previsão de substituição até 2015; propostas que contemplassem a diversidade regional do país; consideração à variedade de modelos de documentos curriculares identificados no levantamento geral.

4 BRASIL. Lei no 9.394/1996, de Diretrizes e Bases da Educação Nacional, Art. 26. Os currículos do ensino fundamental e médio devem ter uma base nacional comum, a ser complementada, em cada sistema de ensino e estabelecimento escolar, por uma parte diversificada, exigida pelas características regionais e locais da sociedade, da cultura, da economia e da clientela. 
Pesquisa (BATISTA; LUGLI; RIBEIRO, 2015) que buscou compreender as diversas posições de atores como especialistas e gestores públicos no debate sobre padronização do currículo no Brasil mostrou que é dada grande relevância à articulação entre conteúdos universais e locais em meio aos conteúdos dos componentes curriculares. Diante disso - e da própria orientação do campo normativo -, era de se esperar que a parte diversificada estivesse bastante presente nos documentos curriculares, de modo que o conhecimento sobre o local fosse, de algum modo, contemplado. Essa incorporação nos conteúdos das disciplinas é, no entanto, limitada.

A maior parte dos 16 conjuntos de documentos analisados menciona de forma genérica que a parte diversificada deveria se constituir em temas transversais ou então que é papel da escola e dos professores efetivar a contextualização dos conhecimentos previstos no documento. Mesmo quando se recorre a eixos temáticos para organizar as relações entre as disciplinas, isso não resulta em maior destaque para as dimensões sociais, econômicas, naturais ou culturais do estado. Verifica-se que apenas Maranhão, Mato Grosso, Pernambuco e Roraima contemplam de algum modo nos conteúdos algum conhecimento específico referente ao estado. Mato Grosso, por sinal, é o único estado que justifica a elaboração de um documento próprio a partir da constatação de que os documentos federais disponíveis não atendem adequadamente às suas características locais.

Observa-se nos estados uma tendência a estabelecer uma "base comum" com conteúdos mínimos e universais, à qual escolas e professores são chamados a acrescentar as particularidades de cada local, sem que haja detalhamento relativo a tais particularidades.

No documento da Bahia, por exemplo, os anos finais do ensino fundamental possuem uma organização específica, em que há uma parte diversificada concebida mediante "eixos temáticos" e "focos", de forma que se orienta mais diretamente o que o professor e a escola devem trabalhar em termos de conteúdos que se reportam à parte diversificada. De acordo com o documento, a adoção de eixos temáticos na parte diversificada permite um diálogo entre a base nacional comum e a parte diversificada, podendo a escola escolher até quatro eixos, entre educação ambiental, linguagens e comunicação, identidade e cultura, ciência e tecnologia e cidadania. 


\section{A ABORDAGEM DA QUESTÃO DA DIVERSIDADE}

Para compreender a que se refere o termo diversidade no contexto das recomendações e políticas curriculares é preciso remeter diretamente às Diretrizes Curriculares Nacionais Gerais para a Educação Básica (Parecer CNE/CEB no 7/, 2010) e para o ensino fundamental de 9 anos (Parecer CNE/ CEB no 11/2010), bem como às diversas normativas do Conselho Nacional de Educação referentes ao currículo nas modalidades de ensino das diferentes etapas da educação básica. Pode-se assinalar que, nesses três documentos nacionais, há três modos de compreender a temática da diversidade:

1. Como contextualização dos conteúdos de ensino à cultura local - adequação dos objetivos e conteúdos previstos no documento curricular ao meio em que está inserida a escola à vivência dos alunos; atenção às peculiaridades locais e regionais, atendendo a demandas sociais e educacionais específicas.

2. Como princípio previsto nas Diretrizes Curriculares Nacionais (DCN) e como parte da discussão dos direitos humanos, o direito à diferença, o que requer mais do que a simples tolerância e o respeito ao outro. Recomenda o "respeito à pluralidade e diversidade de nacionalidade, etnia, gênero, classe social, cultura, crença religiosa, orientação sexual e opção política, ou qualquer outra diferença, combatendo e eliminando toda forma de discriminação" (Parecer CNE/CEB nํ5/ 2011).

3. Como adequação do ensino comum a condições específicas de operação das escolas (escolas indígenas, quilombolas, Educação de Jovens e Adultos [EJA], Educação das Pessoas com Necessidades Especiais, por exemplo), abordagem que tende a tomar a diversidade como a própria oferta das modalidades de ensino.

As diferentes apropriações dos temas da diversidade no conjunto de documentos analisados evidenciam como essas questões ganham ênfase enquanto princípio educativo que percorre o conjunto de conteúdos que pode então ser comum a todos ou apresentar-se como modalidade de ensino para o atendimento de populações diferenciadas.

Em Pernambuco, Educação em Direitos Humanos constitui o eixo organizador do documento curricular. $\mathrm{Na}$ introdução comum a todos os cadernos que detalham os componentes curriculares, a Secretaria Executiva de Desenvolvimento da Educação afirma esperar que a Educação em Direitos 
Humanos "garanta a sistematização dos conhecimentos desenvolvidos na sociedade e o desenvolvimento integral do ser humano" (PERNAMBUCO, 2013, p. 14), ou seja, que atue como elemento de transversalização do currículo. Já em Mato Grosso e Rondônia, Educação em Direitos Humanos está presente como disciplina autônoma.

Analisando os componentes curriculares de Pernambuco, percebem-se tentativas de articulação das disciplinas de modo a produzir algum tipo de inter-relação entre elas. 0 caderno de Orientações Pedagógicas em Direitos Humanos, por exemplo, está organizado em oito eixos, para os quais são apresentados textos e atividades para o trabalho em sala de aula.

Verificou-se a indicação de desenvolvimento dos temas da diversidade em disciplinas e em eixos/unidades específicas nos estados da Bahia, Pernambuco, Maranhão, Rio de Janeiro, Rio Grande do Sul e no Distrito Federal. Nos demais estados que incorporaram os temas da diversidade a seus documentos curriculares, eles são tomados como temas transversais de que as diversas disciplinas se ocupariam, cada uma a seu modo.

Nas páginas que antecedem a apresentação dos conteúdos e competências/ habilidades, o documento curricular de Mato Grosso do Sul discute alguns marcadores ${ }^{5}$ relacionados à diversidade no tópico "Educação, escola e currículo". Em um tópico à parte, denominado "Escolas de regiões de fronteira", discute-se a diversidade que marca a escola situada em região de fronteira com o Paraguai e a Bolívia (são 13 municípios nessa situação) e a importância de o currículo considerá-la. Mato Grosso também contempla Educação Indígena, à qual se somam Educação Quilombola e as temáticas da Educação Ambiental e Educação em Direitos Humanos, objeto de um caderno específico para o trabalho com a diversidade. 0 caderno “Orientações curriculares das diversidades educacionais" (2010) de Mato Grosso dedica uma seção para cada um dos seguintes temas: Educação em Direitos Humanos, Educação para Relações de Gênero e Diversidade Sexual, Educação Ambiental, Educação das Relações Étnico-raciais (com destaque para as questões indígenas, africanidades e afro-brasileira), Educação do Campo, Educação Escolar Quilombola, Educação Escolar Indígena e, por fim, enquadrada como "diversidade", a Educação de Jovens e Adultos.

Educação Especial, na perspectiva da educação inclusiva; Educação Básica do Campo; Educação Escolar Indígena; Educação das Relações Étnico-raciais e Quilombola; Educação em Regime de Privação de Liberdade; Educação para a Igualdade de Gênero; Educação Ambiental e Educação para o Trânsito. 
O Piauí apresenta um item no primeiro volume das Diretrizes Curriculares denominado “Modalidades, Diversidade e Temáticas Sociais". O estado considera que esses temas devem ser trabalhados de modo articulado, com possibilidade de parcerias com as escolas ou instituições sociais. Educação de Jovens e Adultos (EJA), Educação do Campo, Educação Quilombola, Educação Profissional étnico-racial, Educação Escolare Individual, Educação Ambiental, Educação Especial, Educação Prisional, Diversidade Sexual, Trabalho Infantil, Drogas e Álcool, Violência e Educação Indígena compõem uma listagem para “fazer frente à discriminação", ou seja, o relacionamento das escolas com os movimentos sociais é tido como meio para o enfrentamento da discriminação.

Piauí, Rondônia e Paraná são estados que tratam extensamente da diversidade. Em Rondônia, o tratamento dado aos temas indicados varia consideravelmente: tanto em componentes específicos como integrados a disciplinas ou ainda como eixos transversais. Nesse estado, a elaboração curricular para as populações indígenas merece destaque, pois não se trata apenas de abordá-la como uma modalidade específica, mas de chamar a atenção para a quantidade de povos indígenas espalhados pelo território de Rondônia, o que, segundo consta no documento, se apresenta como algo que necessita de atenção especial, tendo em vista que há em torno de cem escolas bilíngues no estado.

No Paraná, constatou-se a presença de textos específicos que completam o conjunto de documentos referentes às disciplinas da grade curricular dos anos finais do ensino fundamental: as Diretrizes Curriculares para a Educação do Campo, a Educação Especial, a Educação de Jovens e Adultos, a Educação Escolar Indígena, a Educação Profissional, a de Gênero e Diversidade Sexual. Esses documentos não têm a mesma organização tópica das disciplinas, em geral descrevem o "estado da arte" do trabalho desenvolvido na modalidade (ou tema), os fundamentos teórico-metodológicos e as implicações curriculares. Além disso, há um conjunto de "Cadernos Temáticos" que problematiza diferentes temas, além de conteúdos referentes a aspectos didático-metodológicos, como: organização do trabalho pedagógico, diretrizes para o uso de tecnologias educacionais, educação a distância, fotografia e audiovisuais, ilustração digital e animação, sexualidade, prevenção ao uso indevido de drogas, educação ambiental, relações étnico-raciais, violência na escola, produção de áudios. 0 tratamento em documentos diferenciados não significa que eles sejam destacados das disciplinas regulares, pois existe a declaração explícita de um princípio de integração que respeite as características propriamente disciplinares, contrária a uma abordagem transversal. 
As questões relacionadas à diversidade são tratadas com alguma profundidade em História, Geografia, Educação Física e Arte no caso do documento do Rio de Janeiro. Há referências à temática nos textos introdutórios dessas disciplinas, em alguns dos eixos temáticos que orientam o trabalho nos diferentes bimestres, bem como em habilidades/competências. Ainda nesse documento, há referência à questão "cultural, étnico-racial e religiosa” na proposição das habilidades/competências, como por exemplo:

"Identificar as principais características étnico-culturais da população brasileira, relacionando-as às matrizes de referência étnica e cultural", para o $7^{\circ}$ ano (RIO DE

JANEIRO, 2012b, p. 6, grifos nossos);

"Caracterizar a base política, econômica, social e cultural das sub-regiões latinoamericanas", para o $8^{\circ}$ ano (RIO DE JANEIRO, 2012b, p. 7, grifos nossos).

"Compreender a diversidade étnica, cultural, religiosa, política, econômica e natural no Oriente Médio", para o $9^{\circ}$ ano (RIO DE JANEIRO, 2012b, p. 8, grifos nossos).

No documento de Geografia, há nesse estado referência também ao “regional” na proposição das seguintes habilidades/competências:

"Identificar os elementos sociais, culturais, econômicos e políticos que conferem identidade às regiões brasileiras, elencando questões que marcam algumas regiões como: a indústria da seca no Nordeste; desmatamento na Amazônia; problemas urbanos no Sudeste etc.", do tema "Organização político-administrativa e divisão regional do Brasil”, $7^{\circ}$ ano (RIO DE JANEIRO, 2012b, p. 6).

O Acre trata as questões da diversidade em um material separado do documento nominado orientações curriculares. Essa discussão é feita em um projeto denominado "Asas da Florestania”, em curso desde 2005 para o ensino fundamental, desde 2008 para o ensino médio e, a partir de 2009, para a educação infantil ${ }^{6}$. Trabalha com metodologia e materiais pedagógicos específicos às escolas rurais, adequados às aulas e às realidades das comunidades e das famílias, incluindo temas regionalizados que visam contribuir para a melhoria da qualidade de vida nas comunidades rurais.

O documento curricular de Goiás é o único em que não há menção alguma sobre diversidade. Bahia e Sergipe sugerem que a temática seja tratada de modo transversal no currículo. Em São Paulo, o documento não anuncia o tratamento da questão da diversidade diretamente. Entretanto, nas listagens de conteúdos e habilidades a serem desenvolvidas nos anos/séries, estão

6 Foram analisados dois textos referentes ao projeto "Asas da Florestania". Os textos não trazem indicação de autoria e/ou vinculação institucional, tampouco a data e o local de publicação. As informações constantes no documento foram confirmadas no site da Secretaria de Educação do Estado do Acre. 
presentes assuntos que de alguma maneira tocam nos temas da diversidade ou dos diversos. Além disso, há um debate sobre a necessidade de uma base comum para o estado de São Paulo.

Considerando o conjunto dos documentos, pode-se afirmar que os modos de integração dos temas da diversidade não seguem um padrão, havendo ainda alguns (poucos) documentos que não fazem menção à questão. De maneira geral, percebe-se nos documentos curriculares uma forte influência de proposições acerca do tratamento da diversidade estabelecidas nos Parâmetros Curriculares Nacionais (PCN) e nas DCN, demonstrando, assim, a persistência das orientações de tais documentos no tratamento dessa questão.

Merece atenção o fato de que, em certos estados, o tratamento à diversidade é entendido como trabalho não direcionado a toda a população escolar, mas aos considerados “diversos": aqueles agrupamentos de estudantes que, por suas características específicas, demandam formas de atendimento e abordagem diferenciados, como na educação de indígenas aldeados, quilombolas ou de jovens e adultos.

\section{OS DOCUMENTOS CURRICULARES E AS AVALIAÇÕES EXTERNAS}

A análise dos documentos curriculares estaduais permitiu identificar as recomendações de avaliação neles propostas, atentando para os seus vínculos com as avaliações externas, sejam elas nacionais, internacionais ou dos próprios estados. 0 Quadro 1 mostra as relações explícitas ou inferidas entre os documentos e as avaliações externas.

\begin{tabular}{|l|l|}
\hline \multicolumn{1}{|c|}{ UF } & \multicolumn{1}{c|}{ AVALIAÇÃO EXTERNA } \\
\hline & $\begin{array}{l}\text { Há relações explícitas ou inferidas } \\
\text { entre o documento analisado e as } \\
\text { avaliações externas (internacionais, } \\
\text { nacionais ou estaduais)? }\end{array}$ \\
\hline Acre & Sim. Saeb e Prova Brasil. \\
\hline Alagoas & $\begin{array}{l}\text { Sim. Ideb. Para o ensino médio - } \\
\text { matriz do Enem. }\end{array}$ \\
\hline Bahia & Não. \\
\hline Distrito Federal & $\begin{array}{l}\text { Sim. Só o sistema de avaliação } \\
\text { institucional do ente federativo. }\end{array}$ \\
\hline
\end{tabular}




\begin{tabular}{|c|c|}
\hline Goiás & $\begin{array}{l}\text { Sim. Remete às avaliações estaduais } \\
\text { e federais. }\end{array}$ \\
\hline Maranhão & $\begin{array}{l}\text { Sim. As matrizes das avaliações } \\
\text { assumem o papel de descritores. }\end{array}$ \\
\hline Mato Grosso & Não. \\
\hline Mato Grosso do Sul & Sim. \\
\hline Paraná & $\begin{array}{l}\text { Sim. Não há referência explícita, mas } \\
\text { é visível a correspondência com os } \\
\text { descritores da Prova Brasil. }\end{array}$ \\
\hline Pernambuco & $\begin{array}{l}\text { Sim. O trabalho pedagógico deve } \\
\text { ser ajustado pelos gestores a partir } \\
\text { dos resultados da avaliação em larga } \\
\text { escala. O estado tem um sistema de } \\
\text { avaliação próprio. }\end{array}$ \\
\hline Piauí & $\begin{array}{llr}\text { Sim. Os descritores das avaliações } & \text { aparecem } \\
\text { externas como } & \\
\text { norteadores. } & \\
\end{array}$ \\
\hline Rio de Janeiro & Sim. \\
\hline Rio Grande do Sul & $\begin{array}{l}\text { Sim. Avaliação própria do estado } \\
\text { (Saers) e as demais avaliações } \\
\text { nacionais (Saeb, Prova Brasil e } \\
\text { Encceja). As matrizes estabelecem } \\
\text { um patamar de aprendizagem. }\end{array}$ \\
\hline Rondônia & $\begin{array}{l}\text { Sim. Saeb e sistema próprio Saero, } \\
\text { elaborado em parceria com o Caed. }\end{array}$ \\
\hline São Paulo & $\begin{array}{l}\text { Sim. Estas devem ser parte do } \\
\text { processo de avaliação do ensino. } \\
\text { Matriz do Saresp orienta os } \\
\text { conteúdos. }\end{array}$ \\
\hline Sergipe & Sim. Ideb e Enem. \\
\hline
\end{tabular}

Quadro 1 - Documentos curriculares, avaliação da aprendizagem e avaliação externa, por unidade da federação.

Fonte: Cenpec (2015).

Dez entre os 16 estados (AL, BA, GO, MA, PE, PI, RO, RS, SE e SP) justificam a elaboração de seu documento curricular pela necessidade de melhoria do ensino. Os baixos índices das avaliações externas (Sistema de Avaliação da Educação Básica [Saeb], Índice de Desenvolvimento da Educação Básica 
[Ideb], Prova Brasil) são apresentados para justificar a elaboração do novo documento e a necessidade de melhoria do ensino. Em seis estados (AC, MA, PI, PR, SP e RJ) os descritores das avaliações externas foram identificados como norteadores dos documentos curriculares no que concerne à Língua Portuguesa e Matemática. Os sistemas de avaliações externas estaduais podem, ainda, ser incorporados à avaliação da aprendizagem nas escolas em vários casos (DF, GO, MS, PE, RJ, RO, RS e SP).

Em alguns estados, como São Paulo, Pernambuco e Goiás, os elementos relacionados ao que deve ser ensinado/aprendido aparecem acompanhados de uma coluna indicando "o que deverá ser avaliado" ou as "formas de avaliação", o que parece estar estreitamente articulado à possibilidade de se utilizar parte da própria matriz de currículo como matriz de avaliação, ligada a uma aferição externa dos resultados da aprendizagem.

Os documentos curriculares do Piauí, Maranhão, Acre e Paraná também apresentam matrizes que dispõem não apenas sobre o que se deve aprender, ensinar, mas também avaliar.

Outro exemplo são os documentos do Acre, em que há também quadros de matrizes com uma coluna para a avaliação. No entanto, diferentemente do Piauí e do Maranhão, apesar de reconhecer a importância da avaliação externa para orientar as políticas públicas e até a destinação de recursos, ressalta-se a sua limitação e a centralidade da avaliação realizada pela escola, qualificada como qualitativa, formativa e planejada pelo professor para iluminar as escolhas pedagógicas (ACRE, 2010, p. 19).

O estado do Paraná, além de já ter uma coluna dedicada à avaliação nas suas Diretrizes Curriculares da Educação Básica elaboradas por disciplina, criou o caderno de expectativas de aprendizagem para todas as disciplinas (PARANÁ, 2012). Nele, apesar de não haver referência clara às avaliações externas (Saeb/ Prova Brasil, Exame Nacional do Ensino Médio [Enem]), é também visível a correspondência das expectativas de aprendizagem com os descritores e as habilidades das avaliações externas, em especial com a Prova Brasil.

Alguns estados sugerem aspectos a ser avaliados, mas não há homogeneidade sobre os modos de apresentar a avaliação entre as áreas de conhecimento/ disciplinas no quadro de matriz.

Em Rondônia, de acordo com o documento curricular, a avaliação externa identifica avanços e retrocessos, e a escola "precisa estar preparada para a utilização destes resultados" de modo que haja "um retomar de ações 
previstas no Currículo Escolar e na Proposta Pedagógica, para efetivamente elevar a qualidade da educação no Estado" (RONDÔNIA, 2013, p. 35).

A consonância do documento curricular do Rio de Janeiro com a avaliação externa aparece já na apresentação, quando se afirma que a finalidade do currículo mínimo é orientar, clara e objetivamente, "os itens que não podem faltar no processo de ensino-aprendizagem, em cada disciplina, ano de escolaridade e bimestre" de modo a "garantir uma essência básica comum a todos e que esteja alinhada com as atuais necessidades de ensino, identificadas não apenas nas legislações vigentes, Diretrizes e Parâmetros Curriculares Nacionais, mas também nas matrizes de referência dos principais exames nacionais e estaduais" (RIO DE JANEIRO, 2012a, p. 2). Como referenciais externos prioritários são citados, entre LDB, DCN, PCN e Orientações Curriculares Nacionais (OCN), as matrizes das principais avaliações externas (Enem, Prova Brasil, Saeb e Sistema de Avaliação da Educação do Estado do Rio de Janeiro [Saerj]).

A abordagem da avaliação, nos documentos de São Paulo e de Pernambuco, por exemplo, está em estreita articulação com a avaliação externa, o que, em geral, resulta em menor grau de abertura à iniciativa da escola e de seus agentes na construção do currículo.

A avaliação, na proposta de São Paulo, é descrita com minúcia, orientando, entre outras coisas, o professor a considerar o rendimento dos alunos com base nos indicadores do Saeb e do Sistema de Avaliação de Rendimento Escolar do Estado de São Paulo (Saresp); e a considerar que as avaliações externas do rendimento dos alunos são apenas parte do processo e devem subsidiar 0 sistema de ensino e a comunidade escolar para eventuais alterações visando à melhoria da qualidade de ensino.

O estado de São Paulo declara que é o documento curricular (de todas as disciplinas escolares) que orienta a avaliação externa e não vice-versa, uma vez que os propósitos do currículo são mais abrangentes do que o recorte que é feito na avaliação. Nesse estado, o Saresp (SÃO PAULO, 2009) foi reformulado na fundamentação conceitual e na metodologia, buscando a correspondência de competências cobradas nessa avaliação e os cadernos de Currículo do Estado de São Paulo. Observa-se, analisando os objetivos de aprendizagem, que há de fato estreita relação da matriz do Saresp com os conteúdos a ser ensinados, garantindo a possibilidade de controle sobre o processo de aprendizagem. 
O documento curricular de Pernambuco destaca as avaliações sistêmicas, argumentando que estas teriam como finalidade melhorar a qualidade das aprendizagens de todos os estudantes: “[...] com dados que permitam comparações entre o proposto e o alcançado com a finalidade de manutenção ou redirecionamento da proposta curricular" (PERNAMBUCO, 2012, p. 49).

Como acontece em algumas unidades da federação (DF, GO, MS, PE, RJ, RO, RS e SP), fica visível a relação próxima entre os sistemas de avaliação externa próprios e a avaliação da aprendizagem nas escolas, com prioridade, no caso de Pernambuco, para as disciplinas de Língua Portuguesa e Matemática. Nesse estado, foram criados recentemente os documentos "Padrões de desempenho da educação básica" para as duas disciplinas (PERNAMBUCO, $2014 a, 2014 b)^{7}$, que são objeto de avaliação no que se consideraram as principais etapas da escolarização $\left(3^{\circ}, 5^{\circ}, 7^{\circ}\right.$ e $9^{\circ}$ anos do ensino fundamental e $1^{\circ}$, $2^{\circ}$ e $3^{\circ}$ anos do ensino médio) ${ }^{8}$. Nos Padrões, elaborados, como todos os documentos pernambucanos, com o apoio do Centro de Políticas Públicas e Avaliação da Educação (Caed), explicita-se que professores e gestores devem articular as avaliações em larga escala à elaboração das propostas curriculares, alterando o trabalho pedagógico com base desses resultados.

O documento curricular de Alagoas é menos explicitamente relacionado à avaliação que o do Rio Grande do Sul, considerados modelos de organização semelhantes, indicando nuances entre os estados. No caso do Rio Grande do Sul, o documento faz alusões explícitas e constantes à avaliação em larga escala, tanto de âmbito estadual quanto federal, citando o Sistema de Avaliação do Rendimento Escolar do Rio Grande do Sul (Saers), o que ilustra mais um caso de estado em que há incorporação dos sistemas de avaliação próprios à avaliação da aprendizagem nas escolas. 0 documento reforça a importância da avaliação externa de âmbito federal na consolidação do seu sistema próprio de avaliação. O Saers "é complementar ao sistema nacional de avaliação do rendimento escolar desenvolvido pelo Ministério da Educação" (RIO GRANDE DO SUL, 2009, p. 7). Ao tratar do Saeb e da Prova Brasil, afirmase que "a avaliação é realizada para melhorar a qualidade da educação, para

Numa definição mais simplificada e menos técnica, padrões de desempenho são as expectativas de aprendizagem de cada componente curricular expostas nas matrizes, propondo um patamar de desempenho dos estudantes: nível 1, elementar; nível 2, elementar II; 3, nível básico; e 4, desejável (PERNAMBUCO, 2014a, 2014b).

8 De acordo com Bonamino e Sousa (2012, p. 380), em geral essas propostas envolvem a avaliação censitária das escolas, com aplicação de provas com alunos de $5^{\circ}$ e $9^{\circ}$ anos do ensino fundamental e $3^{\circ}$ ano do ensino médio (final dos ciclos), com frequência bianual. Ver, também, Brooke e Cunha (2011, p. 18). 
que os professores possam, por meio da entrega dos boletins pedagógicos às escolas, apropriar-se dos resultados da avaliação e, com isso, melhorar o processo de ensino-aprendizagem (RIO GRANDE DO SUL, 2009, p. 7).

\section{ESPECIFICIDADES ATRIBUÍDAS AOS ANOS FINAIS DO ENSINO FUNDAMENTAL}

Os anos finais do ensino fundamental, sua identidade, características e foco não se consolidaram como objeto de estudo no país. Essa é uma constatação do estudo financiado pela Fundação Vitor Civita e realizado pela Fundação Carlos Chagas (DAVIS et al., 2012). Levantamento realizado em julho de 2015 no Scielo Brasil com a palavra-chave "ensino fundamental II" mostra que essa realidade não mudou muito desde então: foram identificados apenas dois estudos ${ }^{10}$. Já com a palavra-chave "ensino fundamental" aparecem 154 registros. Nenhum deles apresenta em seu título, especificamente, a expressão "ensino fundamental II" ou "anos finais do ensino fundamental".

Davis et al. (2012) afirmam que essa fase de ensino carece de políticas especificamente destinadas a ela. A LDB não desagregou o ensino fundamental em duas "subetapas" para fins de concepção ou organização. As DCN, de 2010, reconhecem a especificidade, designando-as "fases" do ensino fundamental. Afirma serem os anos finais do ensino fundamental uma fase em que há uma grande mudança na organização do ensino, que passa a ser realizado por meio de especialistas.

Mesmo no interior do Ensino Fundamental, há de se cuidar da fluência da transição da fase dos anos iniciais para a fase dos anos finais, quando a criança passa a ter diversos docentes, que conduzem diferentes componentes e atividades, tornando-se mais complexas a sistemática de estudos e a relação com os professores (BRASIL, 2010, p. 14).

As DCN chamam ainda a atenção para o fato de que o ensino nas duas fases do ensino fundamental é, no país, mais comumente ofertado por redes de ensino distintas, o que deve gerar mecanismos de colaboração visando a sua articulação, como já previsto na Constituição de 1988. As DCN (BRASIL, 2010, p. 54-55) tratam também da necessidade de considerar o momento de desenvolvimento das crianças matriculadas nos anos finais do ensino fundamental e considera que os professores, para essa fase, devem ser especialistas em adolescência e juventude. Compreende-se que a idade esperada de frequência das crianças nos anos finais do ensino fundamental se trata de um momento particular no ciclo de vida.

9 Com a palavra-chave "anos finais do ensino fundamental" nenhum artigo foi identificado.

10 Um dos estudos é sobre sistematização do conhecimento em Educação Física no ensino fundamental 2 e o outro sobre a Educação Estatística no ensino fundamental 2 em uma escola de Lavras, MG. 
A seguir apresenta-se o que se pôde apreender em termos de quais seriam, nos documentos curriculares analisados, as especificidades atribuídas aos anos finais do ensino fundamental considerando sua identidade, características e foco.

Observam-se alguns aspectos que, embora não justificados como tais, podem colaborar para uma maior articulação e organicidade entre as diferentes fases, como: similaridade na estrutura e organização das matrizes curriculares dos anos iniciais e anos finais, ou anos finais e ensino médio, quadros comparativos de habilidades/competências para os anos iniciais e finais do ensino fundamental e apresentação de temas transversais às diferentes fases.

De forma mais explícita, entre os 16 estados analisados foram identificados três que apontam mais claramente em seus fundamentos a necessidade de estabelecer especificidade para os anos finais do ensino fundamental: São Paulo, Distrito Federal e Mato Grosso. 0 documento curricular paulista orienta que sejam consideradas as características cognitivas, afetivas e sociais dos adolescentes, assim como os conteúdos, metodologias e saberes próprios de cada disciplina. Os documentos do Distrito Federal reconhecem também a especificidade do EF 2 em relação ao EF 1, caracterizado como um momento de transição, marcado pela introdução de uma nova lógica organizacional. No caso de Mato Grosso, o ensino fundamental de nove anos é organizado em três ciclos, com duração de três anos cada, caracterizados como Ciclos de Formação Humana que devem atender a fases específicas de desenvolvimento:

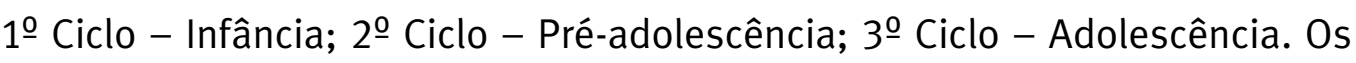
alunos são enturmados segundo idade/fase/ciclo, o que garante, de acordo com a Secretaria de Estado de Educação, a articulação do ensino fundamental. Essa divisão busca deliberadamente superar a segmentação histórica do ensino fundamental mediante a criação do ciclo intermediário, ainda que os anos finais se enquadrem majoritariamente na acepção do $3^{\circ}$ Ciclo, o da adolescência.

A partir da análise feita dos documentos curriculares dos estados e do Distrito Federal e das questões relativas ao EF 2 aqui discutidas, percebese que existe a busca de construir a especificidade do ensino fundamental 2. Por exemplo, quando se observa a busca de um padrão de organização de matrizes curriculares, ou quando encontramos, em alguns documentos, menções ao EF 2 como momento de transição, às peculiaridades da faixa etária dos estudantes, seu ciclo de vida, ou à nova lógica organizacional que se impõe aos professores e estudantes. No entanto, corroborando a dificuldade percebida na consolidação dos estudos e políticas para o EF 2, 
o que a análise aqui empreendida ajuda a destacar é a dificuldade, apesar dos esforços de algumas unidades da federação, de perceber, por meio dos documentos curriculares, um tratamento mais acurado do que seria a chamada "especificidade" dessa fase de ensino.

Aspectos próprios das áreas de conhecimento, concretizados em diferentes formas de pensar, escrever e falar, que introduziriam o aluno no universo discursivo próprio de cada disciplina, em geral, raramente são detalhados. Da mesma forma, falta maior definição quanto aos conhecimentos específicos que devem estar consolidados nessa fase do ensino ou qual a capacidade de autonomia intelectual e acadêmica dos alunos diante de determinados conteúdos em cada período. Em súmula, parte-se do pressuposto de que a transição para o EF 2 ocorre de modo natural.

\section{EM SÍNTESE}

Embora o estudo "Consensos e dissensos em torno de uma Base Nacional Comum Curricular no Brasil" (BATISTA; LUGLI; RIBEIRO, 2015) mostre que a questão da diversidade é central nos argumentos contrários e favoráveis à padronização curricular de atores relevantes que atuam na área da educação, há fraca presença de conteúdos que promovam a construção de identidades plurais nas várias disciplinas que compõem os documentos curriculares analisados. A "diversidade" tende a aparecer dos seguintes modos: como conteúdos que se ensinam para os próprios “diversos” (quilombolas, indígenas, adultos); como orientação geral explícita nos textos iniciais dos documentos curriculares; associada a indicações de que as escolas e professores procedam ao trabalho de identificar os modos pelos quais será tratada, sem que haja explicitação de estratégias e critérios de operacionalização.

Tal como ocorre com o tratamento da questão da diversidade, a tensão entre local e universal também está presente nos documentos curriculares. Nota-se um privilégio no tratamento de conteúdos considerados universais, reservando-se pouco espaço para as questões relacionadas ao regional, estadual e à cultura local. Exceto Mato Grosso, que reconhece a limitação dos documentos produzidos em âmbito federal para o enfrentamento das particularidades e singularidades da realidade mato-grossense, e também o Paraná (que trata essas questões nas disciplinas de Arte, História, Ciências e Geografia), os documentos curriculares tendem a tratar essas questões em separado, em documento à parte daquele organizado em torno de conteúdos universais. Mas vale citar que Maranhão, Mato Grosso, Pernambuco e Roraima 
contemplam nos conteúdos algum conhecimento específico do estado; e a Bahia determinou, para a parte diversificada do currículo, eixos temáticos e focos.

Apenas três dos 16 conjuntos de documentos curriculares analisados explicitam a especificidade que o documento elaborado incorpora para os anos finais do ensino fundamental (SP, MT e DF): como momento de transição (devido à adolescência) em São Paulo, como documento que lida com um ciclo de vida em Mato Grosso ou com uma nova lógica organizacional no Distrito Federal. Ou seja, são documentos que encontram-se alinhados com as orientações das DCN, acima mencionadas, quando elas notificam a relevância de que esses documentos considerem as especificidades da faixa etária atendida por essa fase da educação básica. Chama a atenção o fato de que a maioria não o faça, ressaltando mais uma vez que a invisibilidade do ensino fundamental 2 persiste. Por outro, é preciso dizer que há um grupo de estados que está buscando romper com essa situação.

Observa-se, por fim, um alinhamento dos documentos curriculares com as avaliações externas, evidenciado pela declarada busca de melhoria dos indicadores educacionais e também pela inter-relação entre os descritores das matrizes de avaliação externa e conteúdos de ensino previstos nos componentes curriculares Matemática e Língua Portuguesa. 


\section{State Curricular Documents:}

\section{An Analysis Guided by Topics of the Curricular Debate in Brazil}

Abstract: This article presents the results of one of the studies that integrated the research titled Currículos para os anos finais do ensino fundamental: concepções, modos de implantação e usos [Curricula for the late years of elementary education: conceptions, implementation modes, and uses]. We analyze curricular documents from 16 Brazilian states in the following topics: articulation between universal and local contents; how the diversity issue is approached; relationships between the documents and external evaluations; and how specificities are treated in the late years of primary education. We found that the documents privilege contents that are considered universal to the detriment of the diversified part that would deal with local or regional themes; that most documents do not explain clearly what is the specificity of what is to be learned and taught in the late years of primary education; that most of the documents mention in some way the diversity issue, as promoted by the National Curriculum Parameters (PCNs) and National Curriculum Guidelines (DNCs); however, there is a weak presence of contents that promote the building of plural identities in the various disciplines that form the curricular documents analyzed; and there is a strong influence of external evaluations in the portuguese and mathematics disciplines.

Keywords: Curriculum, late years of primary school, diversity, external assessment. 


\section{Documentos curriculares estatales: un análisis distinguido por temas del debate curricular de Brasil.}

Resumen: En este artículo se presentan los resultados de un estudio que formó parte de la investigación Currículos para los años finales de la enseñanza básica: concepciones, modos de implantación y usos. Se analizan los documentos curriculares de 16 estados brasileños en los siguientes temas: articulación entre contenidos universales y locales, tratamiento de la cuestión de la diversidad; relaciones de los documentos con las evaluaciones externas y tratamiento dado a las especificidades de los años finales de la enseñanza básica. Se llega a la conclusión de que los documentos privilegian contenidos considerados universales en detrimento de la parte diversificada que trataría las cuestiones locales o regionales; que la mayoría de los documentos no explicitan de forma clara cuál es la especificidad de lo que debe aprenderse y enseñarse en los años finales de la enseñanza fundamental; que la mayor parte de los documentos mencionan de algún modo la cuestión de la diversidad, como proclaman los Parámetros Curriculares Nacionales (PCN) y las Directrices Curriculares Nacionales (DCN); pero que hay poca presencia de contenidos que promuevan la construcción de identidades plurales en las diferentes asignaturas que componen los documentos curriculares analizados; y que hay fuerte influencia de las evaluaciones externas sobre las asignaturas de Lengua Portuguesa y Matemáticas.

Palabras clave: Currículo. Enseñanza básica II. Diversidad. Evaluación externa. 


\section{REFERÊNCIAS}

ACRE (Estado). Secretaria de Estado de Educação. Orientações Curriculares para o Ensino Fundamental: Caderno 1 - Arte. Rio Branco: SEE, 2010. (Série Cadernos de Orientação Curricular).

BATISTA, A. A. G.; LUGLI, R. S. G.; RIBEIRO, V. M. Centralização e padronização dos currículos: posições e tomadas de posição. Relatório de pesquisa. São Paulo: Cenpec, 2015. (mimeo).

et al. Currículos para os anos finais do Ensino Fundamental: concepções, modos de implantação e usos. Estudos \& Pesquisas Educacionais, São Paulo, Fundação Victor Civita, n. 5, p. 15-71, 2015.

BONAMINO, A.; SOUSA, S. Z. L. Três gerações de avaliação da educação básica no Brasil: interfaces com o currículo da/na escola. Educação e Pesquisa, São Paulo, v. 38, n. 2, jun. 2012.

BRASIL. Ministério da Educação. Conselho Nacional de Educação. Câmara de Educação Básica. Diretrizes Curriculares Nacionais Gerais para a Educação Básica. Diário Oficial da União, Brasília, DF, 9/7/2010, Seção 1, p. 10. Parecer CNE/CEB nำ 7/2010, aprovado em 7 de abril de 2010.

BRASIL. Lei no 9.394, de 20 de Dezembro de 1996. Estabelece as Diretrizes e Bases da Educação Nacional. Brasília, DF, 1996.

BRASIL. Secretaria de Educação Fundamental. Parâmetros Curriculares Nacionais: introdução aos parâmetros curriculares nacionais. Brasília : MEC/ SEF, 1997.

BROOKE, N.; CUNHA, M. A. de A. A avaliação externa como instrumento da gestão educacional nos estados. Estudos \& Pesquisas Educacionais, São Paulo, Fundação Victor Civita, n. 2, p. 17-79, 2011.

CENTRO DE ESTUDOS E PESQUISAS EM EDUCAÇÃO, CULTURA E AÇÃO COMUNITÁRIA (CENPEC). Currículos para os anos finais do ensino fundamental: concepções, modos de implantação e usos. São Paulo, 2015, 275p.

DAVIS, C. L. F. et al. Anos finais do ensino fundamental: aproximando-se da configuração atual (relatório final de pesquisa). São Paulo: Fundação Victor Civita, 2012.

MATO GROSSO (Estado). Secretaria de Estado de Educação de Mato Grosso. 
Orientações Curriculares: Concepções para a Educação Básica. Cuiabá: Seduc/MT, 2010.

PARANÁ (Estado). Secretaria de Estado da Educação do Paraná. Departamento de Educação Básica. Caderno de Expectativas de Aprendizagem. Paraná: Seed, 2012.

PERNAMBUCO (Estado). Secretaria de Educação do Estado de Pernambuco. Parâmetros para a educação básica do Estado de Pernambuco: Parâmetros Curriculares. Recife: SEE, 2012.

. Secretaria de Educação do Estado de Pernambuco. Parâmetros para a educação básica do Estado de Pernambuco: Parâmetros Curriculares de Língua Inglesa. Ensino Fundamental e Médio. Recife: SEE, 2013.

Secretaria de Educação do Estado de Pernambuco. Parâmetros para educação básica do Estado de Pernambuco: Padrões de Desempenho Estudantil em Língua Portuguesa. Recife: SEE, $2014 a$.

- Secretaria de Educação do Estado de Pernambuco. Parâmetros para educação básica do Estado de Pernambuco: Padrões de Desempenho Estudantil em Matemática. Recife: SEE, 2014b.

RIO DE JANEIRO (Estado). Secretaria de Estado de Educação. Currículo Mínimo: Matemática. Rio de Janeiro: Seeduc, 2012a.

. Secretaria de Estado de Educação. Currículo Mínimo: Geografia. Rio de Janeiro: Seeduc, 2012b.

RIO GRANDEDO SUL (Estado). Secretaria de Estado da Educação. Departamento Pedagógico. Referencial Curricular. Lições do Rio Grande: Linguagens, Códigos e suas Tecnologias - Língua Portuguesa e Literatura, Língua Estrangeira Moderna. Volume 1. Porto Alegre: Seduc, 2009.

RONDÔNIA (Estado). Secretaria de Estado da Educação de Rondônia. Referencial Curricular de Rondônia: Ensino Fundamental. Porto Velho: Seduc, 2013.

SAMPAIO, M. M. F. (Org.). Relatório de análise de propostas curriculares de ensino fundamental e ensino médio. São Paulo; Brasília: MEC/SEB, 2010.

SÃO PAULO. (Estado). Secretaria da Educação do Estado de São Paulo. Matrizes de Referência para Avaliação Saresp. Volume 1. São Paulo: SE, 2009. 
Sobre os autores:

Rosário S. Genta Lugli é doutora em Educação pela Universidade de São Paulo (USP) e docente da Universidade Federal de São Paulo (Unifesp).

gentalugli@gmail.com

Hivy Damasio Araújo Mello é doutora em Sociologia pela Universidade Estadual de Campinas (Unicamp) e pesquisadora do Cenpec.

hivy.mello@cenpec.org.br

Pâmela Felix Freitas é doutoranda em Educação pela USP, mestre em Educação pela mesma instituição e pesquisadora do Cenpec.

pamela.freitas@cenpec.org.br

Luiz Carlos Novaes é doutor em Educação pela Pontifícia Universidade Católica de São Paulo e pós-doutor em Educação pela USP. É docente do Departamento de Educação da Unifesp e coordenador do Programa de Pós-Graduação em Educação na mesma instituição.

luiz.novaes@unifesp.br

Recebido em: abril de 2016

Aprovado em: maio de 2016 